\title{
Sinyal Tranceiver Ultra High Frequency di Lembaga Penyiaran Publik Televisi Republik Indonesia
}

\author{
Adriani $^{\star 1}$ \\ ${ }^{1}$ Program Studi Teknik Elektro Fakultas Teknik Unismuh Makassar \\ e-mail: adriani@unismuh.ac.id
}

\begin{abstract}
The progress of communication that develops according to the times. There is a human desire to be able to improve voice delivery plus moving images known as television. The purpose of this study is to determine the strength of the signal received at a certain location in the TVRI service area of Makassar station based on the field strength of the measurement results and calculation results. The research was conducted by taking measurement data carried out by TVRI in its service areas using a measuring instrument (Field Strength Meter ML 512 A / Anritzu Brand). The measurement areas are the Gowa and Takalar areas. The results of the analysis show that the signal strength that reaches the Gowa area is still good, while in the Takalar area the signal strength is quite good where the noise is already present. From the results of the field strength calculation, the signal strength that reaches the receiver is good, which is above $40 \mathrm{~dB} \mu, \mathrm{V}$. The difference between the measurement and calculation results is caused by several things, such as incorrect reading.
\end{abstract}

Keyword: Tranceiver; Ultra High Frequency; Signal

\section{Abstrak}

Kemajuan komunikasi yang berkembang sesuai dengan kemajuan zaman. terdapat keinginan manusia untuk dapat meningkatkan pengiriman suara ditambah gambar yang bergerak yang dikenal dengan Televisi, Tujuan dari penelitian ini untuk mengetahui besar kuat sinyal yang di terima pada lokasi tertentu dalam daerah layanan TVRI stasiun Makassar berdasarkan kuat medan hasil pengukuran dan hasil perhitungan. Penelitian dilakukan dengan cara mengambil data pengukuran yang dilakukan oleh TVRI pada daerah-daerah layanannya dengan menggunakan alat ukur (Field Strength Meter ML 512 A / Merk Anritzu). Daerah pengukurannya yaitu daerah Gowa dan Takalar. Hasil analisis diketahui kuat sinyal yang sampai ke daerah Gowa masih baik, sedangkan pada daerah Takalar kuat sinyal cukup baik dimana noise sudah ada. Dari hasil perhitungan kuat medan, kuat sinyal yang sampai ke penerima sudah baik yaitu di atas $40 \mathrm{~dB} \mu, \mathrm{V}$. Adanya perbedaan antara hasil pengukuran dan perhitungan disebabkan oleh beberapa hal seperti, pembacaan yang kurang tepat.

Kata kunci: Tranceiver; Ultra High Frequency; Signal

\section{Pendahuluan}

Manusia merupakan makhluk sosial yang memerlukan komunikasi untuk melakukan pertukaran informasi satu dengan yang lain. Manusia juga membutuhkan informasi dari sekitarnya. Kemajuan teknologi komunikasi yang semakin berkembang yang sesuai dengan kemajuan zaman. Dari kemajuan zaman tersebut keinginan manusia untuk meningkatkan pengiriman suara ditambah dengan gambar yang bergerak yang lebih dikenal dengan Televisi.

Televisi yang merupakan salah satu media informasi berkembang dengan sangat cepat, ini dapat dilihat dengan adanya berbagai stasiun televisi baik televisi swasta maupun milik pemerintah. Salah satu televisi milik pemerintah yang ada di makassar adalah TVRI Makassar.

TVRI Makassar kini telah mampu menampilkan siaran lokal sendiri. Dalam pemancarannya, kuat sinyal yang diterima pada satu daerah tertentu dalam lokasi layanannya tidak sama. Ini disebabkan oleh beberapa hal diantaranya letak, tinggi antena penerimanya dan faktor-faktor lain. Kuat sinyal yang sampai pada penerima dapat diketahui berdasarkan dengan kuat medannya. 


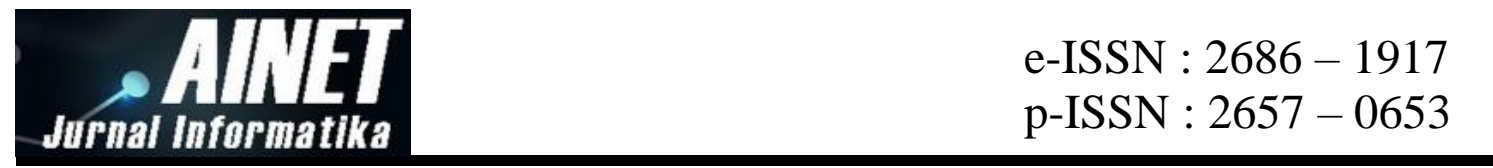

\section{Metode Penelitian}

Penelitian ini dilakukan selama 1 bulan, yang dilaksanakan di LPP TVRI SUL-SEL, yaitu dimulai pada tanggal 01 Desember 2017 sampai dengan tanggal 01 Januari 2018.

Tahapan yang di gunakan dalam penelitian ini di mulai dari pengambilan Data Sampel. Data yang digunakan untuk penelitian ini diperoleh dari berbagai literature, agar data sampel dan data hasil penelitian yang akan diperoleh dapat singkron. Data yang dipergunakan dalam penelitian ini, yaitu pengumpulan data dilakukan dengan membaca literature, baik dari buku maupun dari internet yang ada relevansinya dengan objek yang diteliti.

Tahapan selanjutnya yaitu analisa pengolahan data. Data yang berhasil dikumpulkan, baik data primer (data kasus) maupun data sekunder (teori), akan dianalisa secara kuantitatif, kemudian akan disajikan dalam bentuk deskriptif.

\subsection{Penerimaan Pada Tempat yang Jauh dari Pemancar TV}

Kuat medan yang sampai pada penerima merupakan faktor penentu kualitas penerimaan. Besar kuat medan yang sampai ke penerima dapat menggunakan persamaan (1) :

$$
\mathrm{E}=\frac{88 \sqrt{G \cdot P \cdot h_{t} \cdot h_{r}}}{\lambda d^{2}}
$$

Persamaan (1) menunjukkan rumus yang digunakan untuk menghitung besar kuat medan yang sampai pada pemancar televisi pada sisi penerima. Berdasarkan rumus tersebut, besar kuat medan dipengaruhi oleh besar daya pancar $(P)$. Semakin tinggi daya pancar, maka semakin besar level kuat medan penerimaan siaran televisi.

\begin{tabular}{cc} 
Tabel 1. Standar kuat medan pada penerima & [1] \\
\hline Kuat Medan $(\mathrm{dB} \mu \mathrm{V})$ & Keterangan \\
\hline 80 & Sangat baik \\
60 & Baik \\
40 & Cukup baik \\
20 & Buruk \\
\hline
\end{tabular}

Tabel 1 menunjukkan standar kuat medan pada penerima. Kuat medan dikatakan sangat baik ketika mencapai $80 \mathrm{~dB} \mu \mathrm{V}$ dan buruk ketika mencapai nilai $20 \mathrm{~dB} \mu \mathrm{V}$.

Pada umumnya stasiun relay di Sulawesi Selatan menggunakan antena dipole panel. Jenis antena ini mempunyai pola pancaran seperti dipole biasa yaitu pola pancaran arah belakang dan depan. Besarnya penguatan pada antena dipole panel dapat ditentukan dengan persamaan (2):

$$
G_{n}=G_{d}+10 \log n
$$

\subsection{Perambatan Gelombang Radio}

Perambatan gelombang radio yang dipancarkan memegang peranan yang penting. Hal ini disebabkan karena setiap gelombang radio yang merambat memiliki karakteristik tersendiri.

Gelombang Very Low Frequency (VLF), Low Frequency (LF), dan Medium Wave (MW) lebih cenderung merambat sebagai gelombang tanah. Sedang gelombang High Frequency (HF), lebih menonjol penjalarannya sebagian gelombang langit.

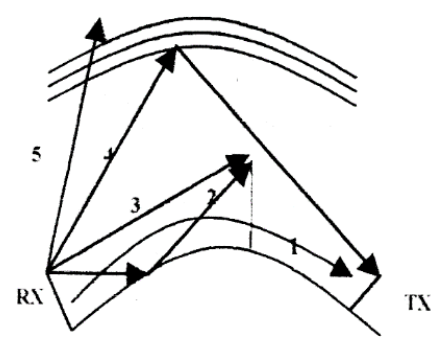

Gambar 1. Perambatan gelombang radio 


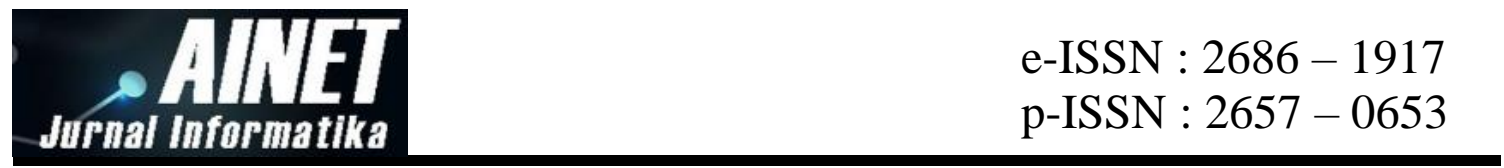

Gambar 1 menunjukkan perambatan gelombang 1. Pada gambar 1 terdapat kode (1) yang merupakan gelombang tanah (ground wave), kode (2) merupakan gelombang ruang (space wave) dan kode (3) yang merupakan gelombang langit (sky wave).

\subsection{Gelombang Tanah (Ground Wave)}

Gelombang tanah (Ground Wave) yaitu gelombang yang menjalar di sepanjang permukaan tanah. Gelombang tanah biasa disebut gelombang permukaan bumi (Surface Wave), cara perambatannya terjadi dipermukaan bumi, dengan demikian disepanjang lintasan dipermukaan bumi, gelombang ini mengalami redaman yang sesuai dengan sifat bumi yang bersifat sebagai tahanan.

\subsection{Gelombang Ruang (Space Wave)}

Gelombang ruang (Space Wave) adalah gelombang yang cara perambatannya secara line of sight. Gelombang ruang menggunakan High Frequency (HF) jarak tempuhnya lebih jauh jika dibandingkan dengan gelombang Medium Frequency (MF) maupun gelombang Very High Frequency (VHF).

Oleh karenanya pada daerah frekuensi diatas $30 \mathrm{MHz}$ gelombang tanah (Ground Wave) mengalami redaman yang sangat besar, sehingga jarak capainya hanya beberapa ratus meter saja. Agar tetap memungkinkan terjadinya komunikasi maka digunakan gelombang ruang (Space Wave).

Pada jarak yang tidak begitu jauh, efek kelengkungan bumi diabaikan atau dianggap datar. Cara perambatan gelombang dengan space wave ini dapat diterangkan seperti terlihat pada gambar 2.

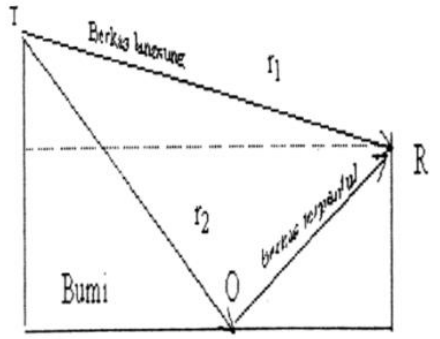

Gambar 2. Perambatan space wave

Gambar 2 menunjukkan model perambatan space wave, dimana efek kelengkungan bumi diabaikan. Pada model perambatan space wave, energi yang mencapai penerima dapat ditempuh dalam dua lintasan. Lintasan pertama, berkas gelombang yang merambat langsung antara pemancar $(T)$ dan penerima $(R)$ yaitu lintasan TR. Lintasan kedua yaitu berkas TOR yang mencapai penerima setelah dipantulkan lebih dahulu oleh permukaan bumi (O).

\subsection{Parameter Hubungan Gelombang Radio}

Ada beberapa yang menjadi parameter hubungan gelombang radio, diantaranya adalah fading, horison radio dan sinyal receiver.

Fading merupakan gangguan yang dialami sinyal yang dirasakan oleh penerima berupa tidak konstannya level penerimaan, sehingga level penerimaan akan bervariasi naik turun sekitar harga tengahnya. Fading biasanya terjadi karena ada beberapa faktor yaitu, direndam benda padat, dipantulkan oleh permukaan kondusif serta pembiasan atmosfir.

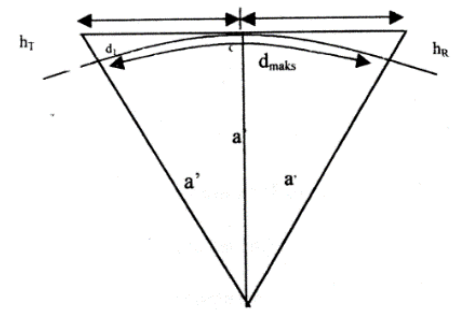

Gambar 3. Jangkauan Propagasi Optis 


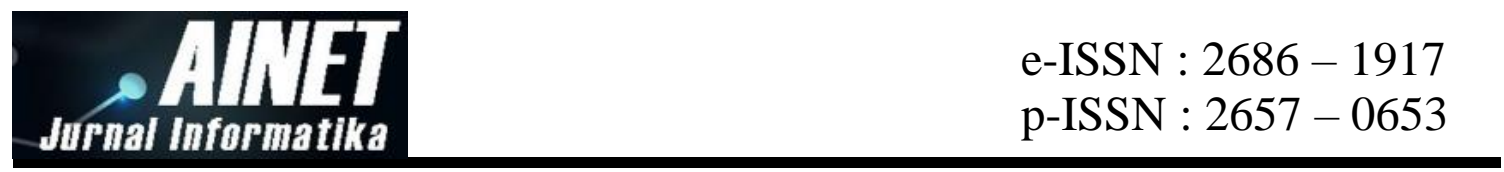

Lengkung bumi mempunyai efek yang lebih penting, yaitu bahwa ia memberikan suatu horison (kaki langit) yang membatasi jangkauan transmisi. Gambar 3 menunjukkan model jangkauan propagasi optis. Jangkauan ini adalah lebih besar dari pada jangkauan optis. Hal ini terjadi karena atmosfir bumi mempunyai pengaruh yang sedemikian sehingga menyebabkan pembelokkan dari gelombang radio, sehingga membawanya melewati batas horisonoptis.

\subsection{Sinyal Receiver}

Sinyal televisi yang merambat melalui jaringan microwave mengalami gangguangangguan berupa redaman-redaman, sehingga sinyal yang sampai pada penerima mengalami penurunan. Hal ini disebabkan oleh beberapa hal diantaranya yaitu penerimaan pada tempat yang jauh dari pemancar televisi dan redaman propagasi.

Daerah-daerah yang terletak jauh dari pemancar televisi, lebih-lebih bila terhalang dengan bukit-bukit atau gunung-gunung tinggi, maka daerah-daerah seperti ini sinyal yang sampai pada antena penerima sangat lemah. Bahkan seringkali daerah-daerah seperti ini lebih besar terkena gangguan sinyal televisi dari pemancar lain yang timbul tenggelam di udara (fading). Bila sinyal televisi pada terminal antena lebih kecil daripada nilai ambang (thereshold), gangguan yang timbul biasanya berupa noise.

\section{Hasil dan diskusi}

\subsection{Gain Antena Pemancar Siaran program TVRI Stasiun Makassar}

Jenis antena yang digunakan pada pemancar siaran program TVRI Makassar yaitu antena tipe Dipole panel dengan penguatan $8 \mathrm{~dB}$ per panel dan daya pancar 5000 watt. Jumlah panel antena pemancar sebanyak 8 buah dengan 4 pengarahan daerah layanannya yaitu daerah Makassar, Gowa, Takalar, Maros, pangkep. Dengan menggunakan persamaan 2 gain dipole untuk tiap daerah dapat diketahui.

$\checkmark \quad$ Gain dipole untuk arah Takalar, jumlah panel 3 buah maka diperoleh:

$$
\begin{aligned}
G_{n} & =G_{d}+10 \log n \\
& =8+10 \log 3 \\
& =12,77 d B
\end{aligned}
$$

$\checkmark \quad$ Gain dipole untuk arah Gowa, jumlah panel 1 buah maka diperoleh:

$$
\begin{aligned}
G_{n} & =G_{d}+10 \log n \\
& =8+10 \log 1 \\
& =8 d B
\end{aligned}
$$

\subsection{Gain antena Penerima Siaran program TVRI Stasiun Makassar}

Kanal yang digunakan dalam sistim pertelevisian Sulawesi Selatan adalah kanal 4-10 dengan frekwensi (174 - 223) MHz. Dengan memperbanyak elemen penyusunnya berarti dapat memperbesar gain suatu antena. Besar gain antena diperlihatkan pada Tabel 2.

\begin{tabular}{cc}
\multicolumn{2}{c}{ Tabel 2. Gain antena Yagi Uda [2] } \\
\hline Jumlah Elemen & Gain Antena (dB) \\
\hline 5 & 9 \\
6 & 9,5 \\
7 & 10 \\
8 & 10,5 \\
12 & 11,5 \\
\hline
\end{tabular}

\subsection{Perhitungan Propagasi}

Perambatan sinyal televisi mengalami redaman yang terdiri dari redaman ruang bebas, redaman saluran, redaman fading dan redaman akibat penghalang.

Pada pemancar stasiun Makassar, jenis kabel yang digunakan adalah kabel koaksial RG 58 redaman saluran 10,2dB/100 meter, panjang saluran 90 m,redaman saluran pemancar yaitu:

$$
\mathrm{a}_{\mathrm{IT}}=\frac{10,2}{100} \times 90=9,18 \mathrm{~dB}
$$


Tabel 3. Redaman ruang bebas untuk tiap daerah pengukuran

\begin{tabular}{|c|c|c|c|}
\hline No & $\begin{array}{c}\text { Lokasi } \\
\text { pengukuran }\end{array}$ & $\begin{array}{r}\text { Redame } \\
\text { Beba }\end{array}$ & $\begin{array}{l}\text { Ruang } \\
\left(a_{0}\right)\end{array}$ \\
\hline 1 & $\begin{array}{l}\text { BLPP } \\
\text { Batang } \\
\text { Kaluku }\end{array}$ & $\begin{array}{c}\text { Vidio } \\
(\mathrm{dB}) \\
96,39\end{array}$ & $\begin{array}{c}\text { Audio } \\
\text { (dB) } \\
96,66\end{array}$ \\
\hline 2 & Malino Kota & 111,08 & 110,75 \\
\hline 3 & Palleko & 104,87 & 104,54 \\
\hline 4 & $\begin{array}{l}\text { Allu Kec } \\
\text { Bangkala }\end{array}$ & 110,5 & 110,17 \\
\hline
\end{tabular}

\subsection{Kuat Medan Penerima Siaran Program TVRI Stasiun Makassar}

Kuat medan penerima siaran program TVRI Stasiun Makassar dapat dilihat pada tabel berikut:

\begin{tabular}{|c|c|c|c|}
\hline \multirow[t]{2}{*}{ No } & \multirow[t]{2}{*}{$\begin{array}{c}\text { Lokasi } \\
\text { Pengukuran }\end{array}$} & \multicolumn{2}{|c|}{$\begin{array}{c}\text { Hasil } \\
\text { Pengukuran } \\
(\mathrm{dB} \mu \mathrm{V} / \mathrm{m})\end{array}$} \\
\hline & & Vidio & Audio \\
\hline 1 & $\begin{array}{l}\text { BLPP Batang } \\
\text { Kaluku }\end{array}$ & 73 & 63 \\
\hline 2 & Malino Kota & 49 & 40 \\
\hline 3 & Palleko & 43 & 33 \\
\hline 4 & $\begin{array}{l}\text { Allu Kec } \\
\text { Bangkala }\end{array}$ & 39 & 30 \\
\hline
\end{tabular}

\subsection{Perhitungan Kuat Medan pada Penerima}

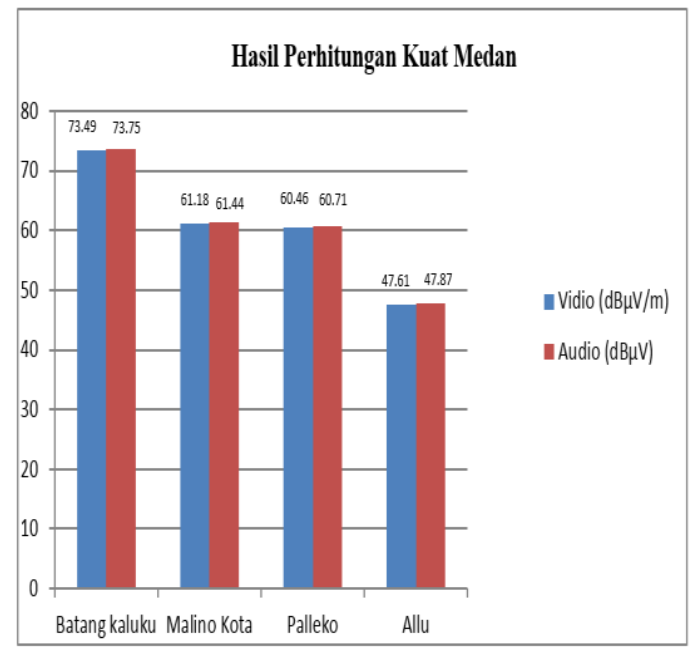

Gambar 4. Hasil perhitungan kuat medan

Dari gambar 4. terlihat bahwa kuat medan hasil pengukuran pada daerah Batang Kaluku kuat medan yang diterima sebesar $73 \mathrm{~dB} \mu \mathrm{V}$ (video) dan $63 \mathrm{~dB} \mu \mathrm{V}$ (audio), penerimaan pada daerah tersebut sudah baik. 


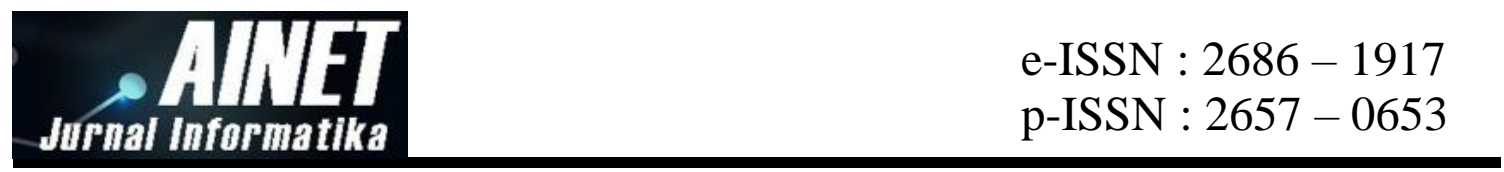

Daerah malino, kuat medan hasil pengukuran sebesar $49 \mathrm{~dB} \mu \mathrm{V}$ (video) dan $40 \mathrm{~dB} \mu \mathrm{V}$ (audio), menunjukkan bahwa kuat sinyal yang diterima masih baik.

Pada daerah Palleko, kuat medan sebesar $43 \mathrm{~dB} \mu \mathrm{V}$ (Video) dan $33 \mathrm{~dB} \mu \mathrm{V}$ (audio), kuat sinyal yang sampai ke penerima baik sedangkan pada sinyal audionya, kuat sinyal yang sampai sudah mulai terganggu (suara ada noise).

Daerah Allu, kuat medan yang diterima untuk video sebesar $39 \mathrm{~dB} \mu \mathrm{V}$ dan audio $30 \mathrm{~dB} \mu \mathrm{V}$, penerimaan sinyal video dan audio, kuat sinyal yang diterima masih cukup baik (noise sudah ada). Dapat dikatakan bahwa kuat sinyal yang sampai ke penerima sudah baik.

Grafik hasil perhitungan, kuat medan yang sampai ke penerima sudah memenuhi standar penerimaan yaitu di atas $40 \mathrm{~dB} \mu \mathrm{V}$. Dapat dikatakan kuat sinyal yang sampai ke penerima sudah baik. Dengan adanya perbedaan antara hasil pengukuran dan hasil perhitungan.kemungkinan bisa disebabkan karena beberapa hal diantaranya pembacaan dan pengarahan antena yang tidak tepat, pengaruh tahanan dalam peralatan itu sendiri.

\section{Kesimpulan}

Kuat sinyal pada daerah layanan TVRI Stasiun Makassar khususnya daerah Batang Kaluku dan Malino Kota sudah baik di atas $40 \mathrm{~dB} \mu \mathrm{V}$, untuk daerah Palleko dan Allu kuat sinyal yang sampai cukup baik yaitu sinyal masih bisa di tangkap meskipun sedikit noise. Sinyal televisi diterima oleh antena harus cukup kuat agar tidak terjadi noise dan tidak menimbulkan derau suara yang cukup keras, oleh karenanya pengarahan antena harus tepat. Semakin jauh jarak penerima dan pemancar maka antena harus setinggi mungkin.

\section{Notasi}

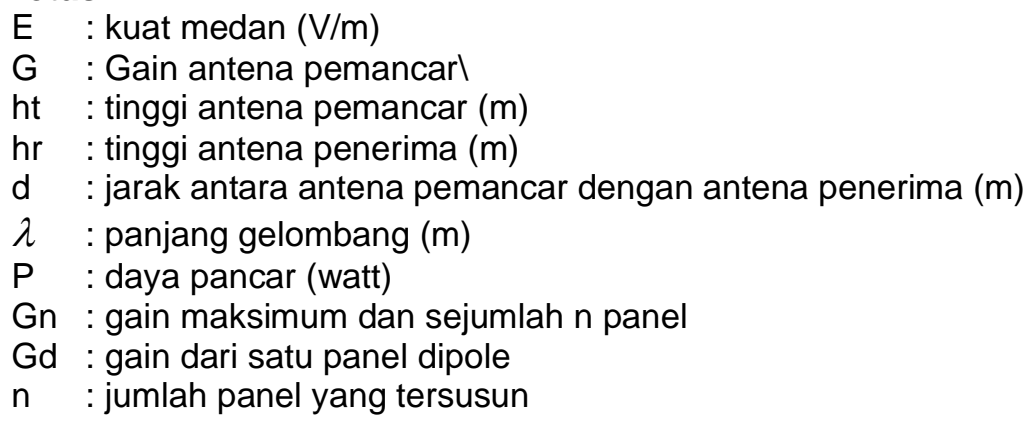

\section{Referensi}

[1] Kennedy, Electronic Communication System Reyner. 2015.

[2] Yanagasiwa and Manabu, Buku Petunjuk Pemancar Televisi. Jakarta: Colombo Plan Expert.

[3] A. A. Irawan, Antena VHF-UHF-Booster. Solo: Aneka, 2016.

[4] H. Brodhage, Planning and engineering of radio relay links. Heyden, 2016.

[5] R. L. Freeman, Radio System Design for Teecomunications. 2016.

[6] Roddy, Dennis, K. Idris, and J. Coolen, Komunikasi Elektronika, Jilid 2. Surabaya: Erlangga, 2015.

[7] Suhana and S. Shoji, Buku Pegangan Teknik Telekomunikasi. Jakarta: PT. Pradya Paramita, 2016.

[8] Simanjuntak, Dasar - Dasar Telekomunikasi. Bandungq: PT. Alumni, 2016. 